\section{On target}

\section{R. V. Jones}

Inventing Accuracy: A Historical Sociology of Nuclear Missile Guidance. By Donald Mackenzie. MIT Press: 1991. Pp.464. £19.95, \$40.50.

A воок on inertial guidance by a sociologist might plausibly be assumed to deal with such matters as how to persuade a stubborn market to embrace some new product. It is therefore refreshing to find in Inventing Accuracy sociologist Donald Mackenzie surveying with authority and insight the development of the guidance systems that make intercontinental ballistic missiles (ICBMs) such a dominating threat.

A basic problem of ICBM guidance is how precisely can the 'brain' of a missile determine its position in flight, and hence guide it to the intended target. In free space the problem can in principle be solved purely from internal data provided by directional sensors and accelerometers in three orthogonal dimensions, with double integrations of acceleration data to establish displacement from the starting point. Such a system which can be independent of radio aids and so invulnerable to radio countermeasures was used in the German V-2 rocket, which used gyroscopes not only as direction indicators but also as accelerometers when mounted in pendulous suspensions which caused them to precess when accelerated. After 1945 these ideas were successfully developed in America for intercontinental missiles, thanks to superb efforts by the American gyroscope designer G. S. Draper; the Russians, too, took up the German work.

In practice, inertial guidance is complicated by the Earth's gravity and by Einstein's equivalence of gravity and acceleration in an isolated system; and physicists as renowned as G. Gamow and P. M. S. Blackett accordingly objected to the proposal that their effects could be disentangled. But because relevant data concerning the Earth's gravitational field could be pre-stored in a missile's 'brain' it proved possible to allow for the cumulative effects of gravity in computing the missile's position. Mackenzie describes how Draper won the argument with Gamow, and proceeded to make gyroscopes with the performance necessary to guide intercontinental missiles to within $\mathrm{H}$-bomb range of their targets. Between 1947 and 1975 Draper reduced the drift rate of gyroscopes 100,000 fold to around $10^{-5}$ degrees per hour by inspired design and immaculate attention to detail. The ultimate design (post-Draper) was an electrostatically suspended free ball; this has, incidently, been further developed for the Stanford Relativity Experiment where a drift rate of $10^{-7}$ degrees per year is the aim.

Besides the Draper-Gamow argument, Mackenzie also describes a controversy between practical men and theorists on how many stars need to be observed for a position on the Earth's surface to be established as a check on inertial navigation. In principle two are needed, but it is possible to 'get away' with one if that one is known from the Nautical Almanack to be vertically over the target at the time when the missile should strike it. This 'Unistar' method depends, of course, on how accurately the true vertical can be established in the moving missile, and 'the problem of the vertical' is a further consequence of the Einstein equivalence.

Although thus dissecting some of the fundamental physical problems in inertial guidance, Mackenzie appreciates also the crucial need for ultra-cleanliness and skilled craftsmanship, quoting from the 1977 report of the Draper Laboratory:

We are concerned over a trend, a national one, that assumes that manual and mechanical skills are no longer necessary in a world populated by computers... that people who are skilled at making things that work are considered expendable... No computer ever made a piece of working hardware. No software ever made a measurement, ground a fitting, sealed a vacuum, cast a bearing, wound a core, heattreated metal, magnetized a spoon, polished a lens, or etched a plate... if the pool of the highly skilled dries up, we would be seriously affected, working as we do in areas where craftsmanship is a principal ingredient.

Such was the skill involved that it "takes about six months and 300,000 dollars to rebuild an MX accelerometer" - to be used in triplicate in the MX missile to give a probable error of about 0.06 nautical miles at $6,000-$ 7,000-NM range.

Although the MX, like Minute Man, was sponsored by the US Air Force, the US Army had long been in the ICBM field building on the German V-2 work with the Jupiter missile and the Saturn booster that launched the Moon shots, whereas the US Navy had Polaris and Trident. Mackenzie attends with insight to the rivalries and jostlings between the three US services, with the US Navy adopting Polaris depite its previous condem- nation of the destruction of cities because it would give the Navy a say in national nuclear strategy.

There were rivalries and jostlings, too, between the proponents of the various types of gyroscope (including lasers) and accelerometers; and Mackenzie also points to differences in the US and Russian approaches, with the Russians rejecting the 'Unistar' technique, relying less on complex software, and preferring gas-bearings rather than fluid-flotation gyroscopes. It emerges, incidentally, that the MOM compass seemingly used by the Russians and made in Hungary is "the best commercial gyrocompass in the world", with the grinding of its ball-bearing raceways "superior to that available in the West at the time". Mackenzie remarks the special aptitude of women for the painstaking assembly of precision components on production lines, and also records that although in 1965 only 3.1 per cent of the scientists and engineers employed by NASA were women, the figure had risen to 10.2 per cent by 1987 .

Inventing Accuracyis the product of thorough research into a wide range of aspects, and it provokes thought in many directions ranging from the technical (for example, a hypothetical 'Schuler' pendulum of length equal to the Earth's radius would have the same period as a satellite orbiting at ground level), to the human and political. In an epilogue its author concludes that "After a half century of 'thinking the unthinkable' - pondering nuclear holocaust - the time has surely now come to think the other unthinkable, a feasible world permanently free of nuclear weapons". And, we might add, all other weapons of devastation. Until then, we must cling to Winston Churchill's hope that "we shall by a process of sublime irony have reach a stage in this story where safety will be the sturdy child of terror and survival the twin brother of annihilation."

R. V. Jones is at 8 Queen's Terrace, Aberdeen $A B 11 X L$, UK

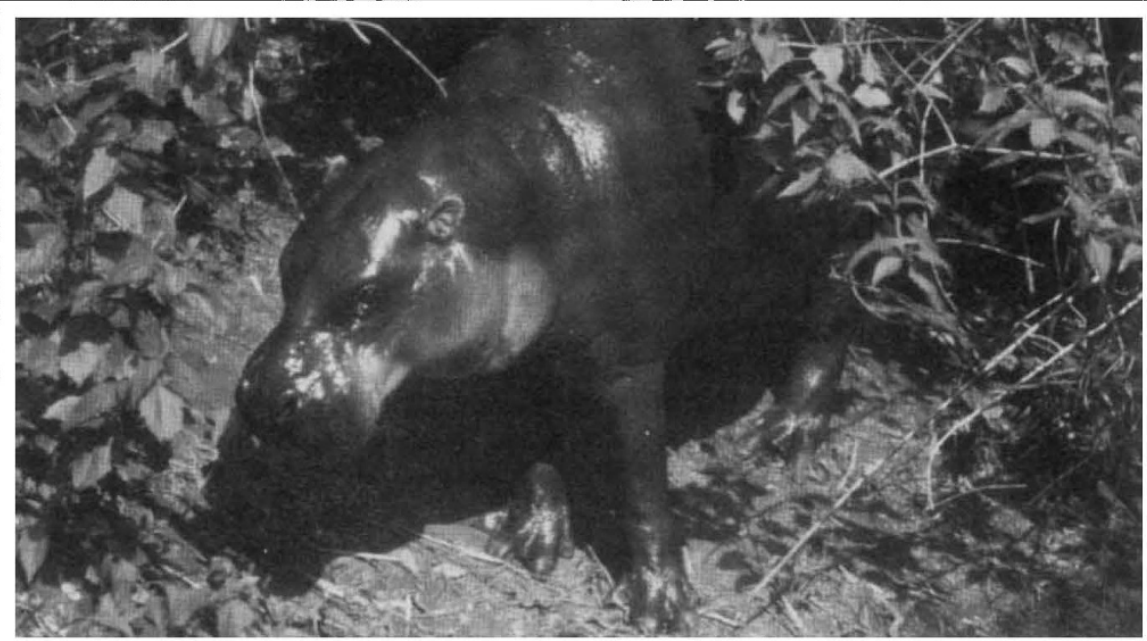

A rare photograph of a pygmy hippopotamus. Its limited distribution in West Africa makes it an endangered species. From The Rainforests of West Africa by Claude Martin (Birkhäuser, SFR 72, DM86). 